\title{
BMJ Open Is decreased lung function associated with chronic kidney disease? A retrospective cohort study in Korea
}

\author{
Soo Kyoung Kim, ${ }^{1}$ Ji Cheol Bae, ${ }^{2}$ Jong-Ha Baek, ${ }^{1}$ Kyu Yeon Hur, ${ }^{3}$ Moon-Kyu Lee, ${ }^{3}$ \\ Jae Hyeon $\mathrm{Kim}^{3}$
}

To cite: Kim SK, Bae JC, Baek J-H, et al. Is decreased lung function associated with chronic kidney disease? A retrospective cohort study in Korea. BMJ Open 2018;8:e018928. doi:10.1136/ bmjopen-2017-018928

- Prepublication history for this paper is available online. To view these files, please visit the journal online (http://dx.doi. org/10.1136/bmjopen-2017018928).

Received 31 July 2017 Revised 27 February 2018 Accepted 9 March 2018

\section{Check for updates}

${ }^{1}$ Division of Endocrinology and Metabolism, Department of Medicine, Gyeongsang National University Hospital, Gyeongsang National University School of Medicine, Jinju, Republic of Korea

${ }^{2}$ Division of Endocrinology and Metabolism, Department of Medicine, Samsung Changwon Hospital, Sungkyunkwan University School of Medicine, Changwon, Republic of Korea ${ }^{3}$ Division of Endocrinology and Metabolism, Department of Medicine, Samsung Medical Center, Sungkyunkwan University School of Medicine, Seoul, Republic of Korea

Correspondence to Dr Jae Hyeon Kim; jaehyeon@skku.edu

\section{ABSTRACT}

Objective There is some evidence that lung function and chronic kidney disease (CKD) may be related. We evaluated the impact of lung function on the development of CKD in a large-scale longitudinal study.

Method Retrospective longitudinal analyses were conducted among subjects who participated in comprehensive health check-ups at least four times during 7 years (between 2006 and 2012). We investigated the development of CKD during the follow-up period according to lung function status.

Results Ten thousand one hundred and twenty-eight individuals (mean age $=51.2$ years) without CKD at baseline were enrolled. During the mean follow-up of 5 years (58.5 \pm 14.4 months), 167 of the 10128 subjects (1.6\%) developed CKD. Multivariable Cox proportional hazards analyses adjusting for age, sex, body mass index, systolic blood pressure, fasting glucose, estimated glomerular filtration rate, uric acid, triglycerides, serum albumin, and the presence of diabetes and hypertension revealed that a decrease of $10 \%$ in the forced expiratory

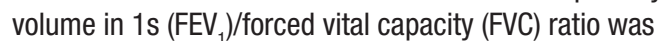
associated with a $35 \%$ increase in the development of CKD during the follow-up. The incidence of CKD was higher in those with an $\mathrm{FEV}_{1} / \mathrm{FVC}$ ratio $<0.8$ compared with those with $\mathrm{FEV}_{1} / \mathrm{FVC}$ ratio $\geq 0.8(\mathrm{HR}=1.454 ; 95 \% \mathrm{Cl} 1.042$ to $2.028, p=0.028$ )

Conclusions Limited airflow as measured by the $\mathrm{FEV}_{1}$ / FVC ratio was associated with an increased risk of CKD.

\section{INTRODUCTION}

Chronic kidney disease (CKD) is an increasing public health problem in Korea and is associated with significant morbidity and mortality. ${ }^{1-4}$ CKD is linked to various other diseases, including hypertension, diabetes, atherosclerosis and metabolic syndrome (MetS). ${ }^{6}$ Chronic obstructive pulmonary disease (COPD) is a systemic inflammatory disease. $^{7}$ It is known that cardiovascular disease, osteoporosis, diabetes and MetS are systemic effects caused by COPD and also its comorbidities. ${ }^{78}$ Proinflammatory cytokines, including tumour necrosis factor $\alpha$ and interleukin 6 , induce insulin resistance by blocking signalling via the insulin receptor, thereby

\section{Strengths and limitations of this study}

The strengths of this study are the large sample and longitudinal nature of the study.

- This study is one of few studies on the relationship between lung function and chronic kidney disease development.

- Limitations of this study are its retrospective nature and failure to note symptoms of any airway disease.

- Another limitation of this study is that most patients had normal pulmonary function; thus it needs further study in patients with chronic obstructive pulmonary disease.

increasing the risk of type 2 diabetes and MetS in patients with COPD. ${ }^{8}$ However, only a few studies have examined the association between renal function and lung function, and found that kidney dysfunction is more common in patients with COPD. ${ }^{9-13}$ These studies suggest that CKD is associated with COPD. However, few studies have explored the relationship between lung function and the incidence of CKD. Thus, we examined cross-sectional and longitudinal associations between lung function, measured by calculating forced vital capacity (FVC), forced expiratory volume in $1 \mathrm{~s}\left(\mathrm{FEV}_{1}\right)$, or the $\mathrm{FEV}_{1} /$ FVC ratio, and the development of CKD after adjusting for other risk factors for CKD.

\section{METHODS}

Study population and data collection

This was a retrospective longitudinal cohort study. Many people undergo comprehensive health check-ups each year at the Samsung Medical Center. Initial data were obtained from 25170 individuals who participated in comprehensive health check-ups at least four times over 7 years (between January 2006 and December 2012). The data from the first visits served as baseline data. In total, 15042 subjects were excluded for the following reasons: (1) 
missing pulmonary function test $(\mathrm{n}=3370),(2)$ age $<20$ years $(\mathrm{n}=7)$, (3) body mass index $(\mathrm{BMI})<18.5 \mathrm{~kg} / \mathrm{m}^{2}$ $(\mathrm{n}=456)$, (4) CKD evident at baseline ( $\mathrm{n}=965)$, (5) missing urine albumin/Cr ratio $(\mathrm{n}=6249)$ and (6) current smoker $(n=3995)$. We excluded current smokers from this analysis because smoking itself has a significant effect on lung function. It would have been difficult to correctly evaluate the association between lung function and the development of CKD if we included current smokers in the study. A total of 10128 individuals (mean age 51.2 years) without CKD at baseline were enrolled.

\section{Measurements}

All subjects fasted overnight, and blood was collected subsequently. All laboratory tests were performed in the central certified laboratory of Samsung Medical Center. Anthropometric and other biochemical variables were measured as described previously. ${ }^{13}$ We measured serum creatinine using the kinetic alkaline picrate method (Jaffe reaction; Roche Modular DP, Roche, Switzerland).

\section{Definition of development of CKD}

The estimated glomerular filtration rate (eGFR) was calculated using the Chronic Kidney Disease Epidemiology Collaboration (CKD-EPI) formula. ${ }^{14}$ CKD was defined as an eGFR $<60 \mathrm{~mL} / \mathrm{min} / 1.73 \mathrm{~m}^{2}$ in patients over 40 years old and eGFR $<75 \mathrm{~mL} / \mathrm{min} / 1.73 \mathrm{~m}^{2}$ in patients younger than 40 years old. ${ }^{15}$

\section{Statistical analysis}

Data expressed as mean \pm SEM. Metabolic risk factors, the prevalence of diabetes and other clinical characteristics were compared between subjects who did and did not develop CKD. A Student's t-test was used to compare continuous variables, and the exact $\chi^{2}$ test was used to detect differences between groups. Pearson's correlation analyses were used to generate correlation coefficients between eGFR and other factors. We used multivariable Cox proportional hazards analyses to estimate HRs with 95\% CIs for the development of CKD during follow-up per $10 \%$ decrease in the $\mathrm{FEV}_{1} / \mathrm{FVC}$ ratio. We compared the development of CKD between two groups $\left(\mathrm{FEV}_{1} /\right.$

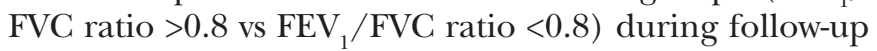
using the HRs for incidences of CKD estimated by Cox proportional hazards analysis. All statistical analyses were performed using Predictive Analytics Software (PASW) (V.17.0; SPSS, Chicago, Illinois, USA). A p value $<0.05$ was considered statistically significant.

\section{Patient and public involvement statement}

This study was a retrospective study. Patients were not involved in this study.

\section{RESULTS}

During the mean follow-up of 5 years (58.5 \pm 14.4 months), 167 of the 10128 subjects (1.6\%) developed CKD. The baseline characteristics of those with and without de novo CKD are shown in table 1 . Those who
Table 1 Baseline characteristics of all subjects by the development of chronic kidney disease (CKD)

\begin{tabular}{|c|c|c|c|}
\hline & $\begin{array}{l}\text { The subjects } \\
\text { who } \\
\text { developed } \\
\text { CKD } \\
(n=167)\end{array}$ & $\begin{array}{l}\text { All other } \\
\text { subjects } \\
(n=9961)\end{array}$ & $P$ values \\
\hline Age (years) & $60.0 \pm 0.8$ & $51.0 \pm 0.1$ & $<0.001$ \\
\hline Sex (male, \%) & $134(80.2 \%)$ & 5749 (57.7\%) & $<0.001$ \\
\hline $\mathrm{BMI}\left(\mathrm{kg} / \mathrm{m}^{2}\right)$ & $24.7 \pm 0.2$ & $23.8 \pm 0.1$ & $<0.001$ \\
\hline $\mathrm{SBP}(\mathrm{mm} \mathrm{Hg})$ & $118.9 \pm 1.3$ & $114.1 \pm 0.2$ & $<0.001$ \\
\hline $\mathrm{DBP}(\mathrm{mm} \mathrm{Hg})$ & $72.5 \pm 0.8$ & $70.6 \pm 0.1$ & 0.022 \\
\hline $\begin{array}{l}\text { Total cholesterol } \\
(\mathrm{mg} / \mathrm{dL})\end{array}$ & $191.8 \pm 2.7$ & $192.7 \pm 0.3$ & 0.733 \\
\hline $\begin{array}{l}\text { Triglyceride } \\
(\mathrm{mg} / \mathrm{dL})\end{array}$ & $142.9 \pm 5.7$ & $122.4 \pm 0.7$ & $<0.001$ \\
\hline $\begin{array}{l}\text { HDL cholesterol } \\
(\mathrm{mg} / \mathrm{dL})\end{array}$ & $54.1 \pm 1.0$ & $57.4 \pm 0.2$ & $<0.001$ \\
\hline $\begin{array}{l}\text { Fasting glucose } \\
(\mathrm{mg} / \mathrm{dL})\end{array}$ & $93.4 \pm 1.2$ & $92.0 \pm 0.2$ & 0.248 \\
\hline $\begin{array}{l}\text { Haemoglobin A } \\
1 \mathrm{c}(\%)\end{array}$ & $5.53 \pm 0.05$ & $5.42 \pm 0.01$ & 0.023 \\
\hline Albumin (mg/L) & $4.25 \pm 0.02$ & $4.31 \pm 0.01$ & 0.001 \\
\hline $\begin{array}{l}\text { Haemoglobin (g/ } \\
\mathrm{dL} \text { ) }\end{array}$ & $14.7 \pm 0.1$ & $14.4 \pm 0.1$ & $<0.001$ \\
\hline Urea (mg/dL) & $15.36 \pm 0.29$ & $13.47 \pm 0.04$ & $<0.001$ \\
\hline Creatinine (mg/dL) & $1.09 \pm 0.01$ & $0.90 \pm 0.01$ & $<0.001$ \\
\hline Uric acid (mg/dL) & $5.92 \pm 0.11$ & $5.15 \pm 0.01$ & $<0.001$ \\
\hline $\begin{array}{l}\text { eGFR }(\mathrm{ml} / \mathrm{min} \text { per } \\
\left.1.73 \mathrm{~m}^{2}\right)\end{array}$ & $69.9 \pm 0.7$ & $88.5 \pm 0.1$ & $<0.001$ \\
\hline hs-CRP (mg/L) & $0.14 \pm 0.02$ & $0.11 \pm 0.01$ & 0.154 \\
\hline FVC (\%) & $93.4 \pm 0.9$ & $95.1 \pm 0.1$ & 0.076 \\
\hline $\mathrm{FEV}_{1}(\%)$ & $100.7 \pm 1.2$ & $103.1 \pm 0.1$ & 0.046 \\
\hline $\mathrm{FEV}_{1} / \mathrm{FVC}$ ratio & $0.77 \pm 0.52$ & $0.81 \pm 0.06$ & $<0.001$ \\
\hline $\begin{array}{l}\text { Diabetes } \\
\text { mellitus (\%) }\end{array}$ & $14(8.4 \%)$ & 583 (5.9\%) & 0.182 \\
\hline Hypertension (\%) & 66 (40.7\%) & 1602 (16.1\%) & $<0.001$ \\
\hline
\end{tabular}

BMI, body mass index; DBP, diastolic blood pressure; eGFR, estimated glomerular filtration rate; $\mathrm{FEV}_{1}$, forced expiratory volume in 1s; FVC, forced vital capacity; hs-CRP, high-sensitivity $\mathrm{C}$ reactive protein; SBP, systolic blood pressure.

developed CKD during the follow-up were significantly older and had a higher baseline BMI, higher triglyceride (Tg) levels and higher blood pressure (table 1). These subjects also had a lower baseline eGFR and $\mathrm{FEV}_{1} / \mathrm{FVC}$ ratio (table 1 ). In addition, the incidence of hypertension at baseline was higher in subjects who developed CKD (table 1).

The baseline eGFR correlated negatively with age, BMI, systolic blood pressure (SBP), total cholesterol, Hemoglobin A1c (HbA1c), uric acid, and high-sensitivity $\mathrm{C}$ reactive protein (hs-CRP). Conversely, eGFR correlated positively with High-density lipoprotein cholesterol 


\begin{tabular}{lll}
\hline $\begin{array}{l}\text { Table } 2 \text { Correlation between the eGFR and risk factors for } \\
\text { chronic kidney disease }\end{array}$ & $\begin{array}{l}\text { eGFR } \\
\text { (n=10128) }\end{array}$ \\
\cline { 2 - 3 } & $\begin{array}{l}\text { Correlation } \\
\text { coefficient }\end{array}$ & P values \\
\hline Variable & -0.417 & $<0.001$ \\
\hline Age (years) & -0.153 & $<0.001$ \\
\hline BMI (kg/m $\left.{ }^{2}\right)$ & -0.078 & $<0.001$ \\
\hline SBP (mm Hg) & -0.032 & 0.840 \\
\hline Fasting glucose (mg/dL) & -0.093 & $<0.001$ \\
\hline Albumin (mg/dL) & -0.063 & $<0.001$ \\
\hline Total cholesterol (mg/dL) & -0.053 & $<0.001$ \\
\hline Triglyceride (mg/dL) & 0.073 & $<0.001$ \\
\hline HDL cholesterol (mg/dL) & -0.062 & $<0.001$ \\
\hline HbA1c (\%) & -0.304 & $<0.001$ \\
\hline Uric acid (mg/dL) & -0.018 & 0.030 \\
\hline hs-CRP (mg/L) & -0.245 & $<0.001$ \\
\hline Haemoglobin (g/dL) & -0.033 & $<0.001$ \\
\hline Baseline FVC (\%) & -0.034 & $<0.001$ \\
\hline Baseline FEV (\%) & 0.175 & $<0.001$ \\
\hline FEV $/$ FVC ratio & & \\
\hline
\end{tabular}

BMI, body mass index; eGFR, estimated glomerular filtration rate; $\mathrm{FEV}_{1}$, forced expiratory volume in 1s; FVC, forced vital capacity; hs-CRP, high-sensitivity $\mathrm{C}$ reactive protein; SBP, systolic blood pressure.

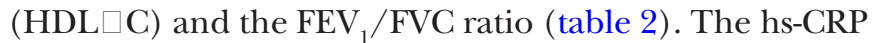
level correlated negatively with FVC $(r=-0.043, p<0.001)$, $\mathrm{FEV}_{1}(\mathrm{r}=-0.041, \mathrm{p}<0.001)$ and $\mathrm{FEV}_{1} / \mathrm{FVC}$ ratio $(\mathrm{r}=$ $-0.020, \mathrm{p}<0.001)$.

After adjustment for risk factors for $\mathrm{CKD}$, including age, sex, BMI, eGFR, fasting glucose, haemoglobin, uric acid, serum albumin, Tg, SBP and the presence of diabetes and/or hypertension, the risk of developing CKD increased as the $\mathrm{FEV}_{1} / \mathrm{FVC}$ ratio decreased (table 3). The HR for the incidence of CKD with a $10 \%$ decrease in the $\mathrm{FEV}_{1} / \mathrm{FVC}$ ratio was 1.346. A lower baseline $\mathrm{FEV}_{1} / \mathrm{FVC}$ ratio was associated with the development of CKD even after adjusting for risk factors for CKD. We divided the subjects into two groups according to $\mathrm{FEV}_{1} / \mathrm{FVC}$ ratios $(<0.8$ and $\geq 0.8)$. The incidence of CKD was $2.8 \%$ and $1.0 \%$, respectively. Age, sex, BMI, eGFR, SBP, levels of haemoglobin, albumin, uric acid, $\mathrm{Tg}$, fasting glucose, the presence of diabetes and the hypertension-adjusted risk of developing CKD were higher in those with an $\mathrm{FEV}_{1} / \mathrm{FVC}$ ratio less than 0.8 compared with those with an $\mathrm{FEV}_{1} / \mathrm{FVC}$ ratio greater than $0.8(\mathrm{HR}=1.454 ; 95 \%$ CI 1.042 to $2.028, \mathrm{p}=0.028$; figure 1).

\section{DISCUSSION}

We found that lower $\mathrm{FEV}_{1} / \mathrm{FVC}$ ratio was associated with an increased risk of $\mathrm{CKD}$ during the mean follow-up of 5
Table 3 HR for incident chronic kidney disease by a 10 decrement in the FVC/FEV 1 ratio

\begin{tabular}{lcll}
\hline Variable & & $\begin{array}{l}\text { HR } \\
\mathbf{( 9 5 \%} \mathbf{C l})\end{array}$ & P values \\
\hline $\begin{array}{l}\text { Crude model } \\
(95 \% \mathrm{Cl})\end{array}$ & 1 & $2.136(1.787$ to 2.552$)$ & $<0.001$ \\
\hline $\begin{array}{l}\text { Adjusted } \\
(95 \% \mathrm{Cl})\end{array}$ & 1 & & \\
\hline Model 1 & 1 & $1.419(1.126$ to 1.788$)$ & 0.003 \\
\hline Model 2 & 1 & $1.384(1.091$ to 1.755$)$ & 0.007 \\
\hline Model 3 & 1 & $1.346(1.062$ to 1.705$)$ & 0.014 \\
\hline
\end{tabular}

Multivariate model 1: adjusted for age, sex, body mass index and the estimated glomerular filtration rate.

Multivariate model 2: adjusted for the factors of model 1, systolic blood pressure and levels of haemoglobin, albumin, uric acid, triglyceride and fasting glucose.

Multivariate model 3: adjusted for the factors of model 2 and the presence of diabetes or hypertension at baseline.

*By multivariable Cox's proportional hazards analysis.

$\mathrm{FEV}_{1}$, forced expiratory volume in 1s; FVC, forced vital capacity.

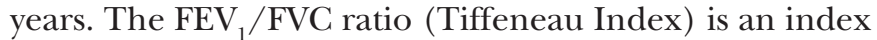
of airflow limitation. ${ }^{16}$ To the best of our knowledge, only a few studies have explored associations between lung function and CKD. Some studies found that kidney dysfunction was more common in patients with COPD. ${ }^{9-12}$ Incalzi et alfound that the prevalence of CKD is increased in patients with COPD, and CKD is a common comorbidity of COPD. ${ }^{9}$ Van Gestel et al also found that COPD was associated with $\mathrm{CKD}$ in patients undergoing vascular surgery. ${ }^{10}$ However, most of these studies were conducted in patients with COPD and had a cross-sectional design. Even less is known about the relationship between lung function and CKD incidence. Chen et al explored the association between COPD and CKD incidence using hospital records and found that the overall incidence of CKD was higher in patients with COPD than patients without COPD. ${ }^{11}$ Our study also showed that subjects with a lower $\mathrm{FEV}_{1} / \mathrm{FVC}$ ratio were at increased risk of developing CKD. This remained true after adjusting for other known risk factors for CKD. Chen et al used insurance research data, which did not include information on the GFR, pulmonary function or laboratory test results. ${ }^{11}$ Unlike Chen et $a l$, we used the eGFR and pulmonary function test data to define CKD and pulmonary function.

Although our study results may be due to a causal relationship, there are some plausible explanations for this relationship. The lung dysfunction has risk factors in common with CKD including old age, smoking, diabetes, hypertension and obesity. ${ }^{17-19}$ Patients with reduced lung function may have coexisting diabetes, MetS and/or hypertension, which are known risk factors for CKD. ${ }^{20} 21$ We also found that those who developed CKD were more likely to have hypertension and/or dyslipidaemia at baseline and more likely to be older. Baseline age, BMI, HbA1c level and SBP negatively correlated with eGFR. However, reduced lung function $\left(\mathrm{FEV}_{1} / \mathrm{FVC}\right.$ ratio $)$ at 


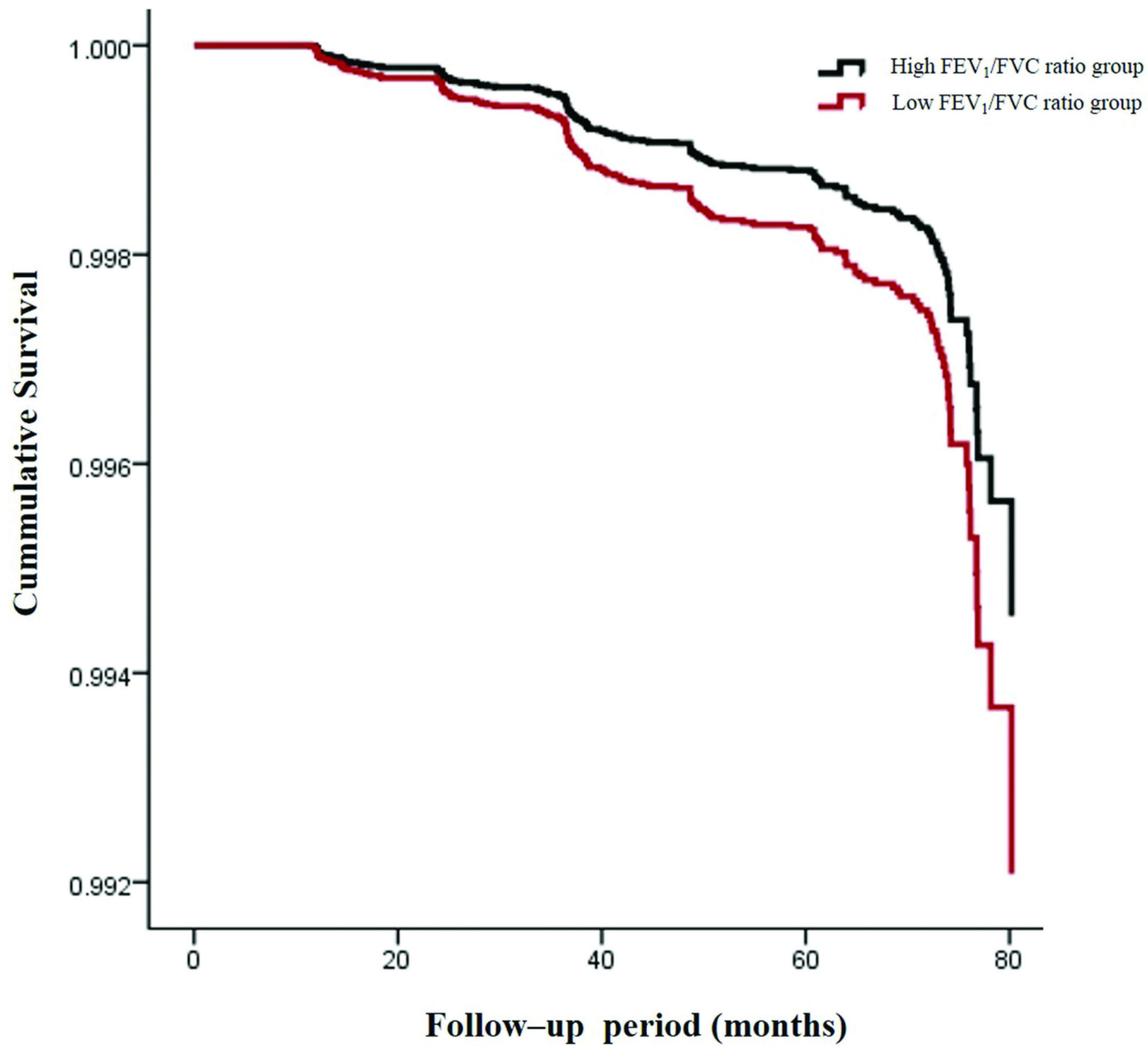

Figure 1 Cumulative survival curve for incident chronic renal failure from values of $\mathrm{FEV}_{1} / \mathrm{FVC}$ ratio. The data are adjusted for age, sex, smoking status, body mass index, estimated glomerular filtration rate, systolic blood pressure, levels of haemoglobin, albumin, uric acid, triglyceride and fasting glucose, and the presence of diabetes and/or hypertension at baseline. Cox's proportional hazards regression model was employed to draw the curves. FEV $_{1}$, forced expiratory volume in 1s; FVC, forced vital capacity.

baseline was associated with CKD development after adjusting for these risk factors although the HR decreases after adjusting other risk factors, and baseline $\mathrm{FEV}_{1} / \mathrm{FVC}$ also positively correlated with eGFR. This implies that lung function affects CKD development. Hypoxaemia or increased oxidative stress caused by decreased lung function could contribute to the development of CKD. Accumulating evidence suggests that renal hypoxia is a key player in the progression of CKD. ${ }^{22}$ Chronic renal hypoxia is closely linked to capillary rarefaction, which affects tubular epithelial cells, fibroblasts and inflammatory cells, resulting in tubulointerstitial fibrosis. ${ }^{23}$ Increased oxidative stress could also contribute to the onset of CKD. Oxidative stress increases the generation of advanced glycation end products (AGEs), which in turn interact with receptors for AGEs (RAGE) ${ }^{24}$ AGEs were increased in patients with COPD, ${ }^{24}$ and one recent study showed that pulmonary and renal endothelial cell injury was linked to increased endothelial AGEs and RAGE. ${ }^{25}$ These studies were done in patients with COPD or COPD animal models, and lung function in our study group was near normal. The attenuated association between $\mathrm{FEV}_{1} /$
FVC and the development of CKD after adjustment for other factors might be explained by the difference in lung function status of subjects in our study and those of other studies.

Systemic inflammation may also be a link between lung dysfunction and CKD. COPD is a systemic inflammatory disease.$^{26}$ Low-grade systemic inflammation was noted in subjects with airflow obstructions. ${ }^{26}$ High serum CRP concentrations have been reported in patients with COPD. ${ }^{27}$ Thus, COPD is a systemic inflammatory disease involving the lungs. Inflammation also plays a role in the development of CKD and is associated with increased levels of inflammatory and procoagulant biomarkers, including CRP and fibrinogen. ${ }^{28}$ Inflammation may trigger the development of CKD in those with lung dysfunction. To understand why lung function was associated with the development of CKD, we explored the association between hs-CRP levels and lung function. The hs-CRP level was negatively associated with the $\mathrm{FEV}_{1} / \mathrm{FVC}$ ratio. This indicates that inflammation may play a role in the relationship between lung dysfunction and CKD. 
Our study has certain limitations. First, all subjects were volunteers, self-scheduling comprehensive health examinations (sometimes annually) for at least 5 years, implying that they were more concerned about their health and therefore not representative of the general population. Second, we used the CKD-EPI equation to estimate GFR, because the Modification of Diet in renal disease (MDRD) equation was developed in subjects with CKD and underestimated GFR. ${ }^{20}$ So the incidence of CKD was low, and we did not assess proteinuria. Thus, we did not analyse the relationship between lung function and proteinuria. Third, the work was retrospective in nature and the symptoms of any airway disease were not noted. Prospective studies are needed to further define these relationships.

We confirmed that the incidence of CKD is increased in patients with airflow limitation, as measured by the $\mathrm{FEV}_{1}$ / FVC ratio. CKD is associated with mortality and morbidity. Therefore, it is important to recognise the relationship between reduced lung function and CKD development in clinical practice.

\section{CONCLUSION}

Limited airflow as measured by the $\mathrm{FEV}_{1} / \mathrm{FVC}$ ratio was associated with an increased risk of CKD. This implies that common pathogenic mechanisms exist between a decline in lung function and the development of CKD. The baseline $\mathrm{FEV}_{1} / \mathrm{FVC}$ ratio could be helpful for identifying individuals at risk for CKD.

Contributors SKK, JHK, JCB: Substantial contributions to the conception or design of the work, or the acquisition, analysis or interpretation of data. J-HB, KYH, M-KL: Drafting the work or revising it critically for important intellectual content. JHK: Final approval of the version published and agreement to be accountable for all aspects of the work in ensuring that questions related to the accuracy or integrity of any part of the work are appropriately investigated and resolved.

Funding This research received no specific grant from any funding agency in the public, commercial or not-for-profit sectors.

Competing interests None declared.

Patient consent Not required.

Ethics approval Ethical Committee of Samsung Medical Center at Sungkyunkwan University, Seoul, Korea.

Provenance and peer review Not commissioned; externally peer reviewed.

Data sharing statement No additional data are available.

Open Access This is an Open Access article distributed in accordance with the Creative Commons Attribution Non Commercial (CC BY-NC 4.0) license, which permits others to distribute, remix, adapt, build upon this work non-commercially, and license their derivative works on different terms, provided the original work is properly cited and the use is non-commercial. See: http://creativecommons.org/ licenses/by-nc/4.0/

(C) Article author(s) (or their employer(s) unless otherwise stated in the text of the article) 2018. All rights reserved. No commercial use is permitted unless otherwise expressly granted.

\section{REFERENCES}

1. Park CW. Diabetic kidney disease: from epidemiology to clinical perspectives. Diabetes Metab J 2014;38:252-60.
2. Perkins RM, Bucaloiu ID, Kirchner HL, et al. GFR decline and mortality risk among patients with chronic kidney disease. Clin J Am Soc Nephrol 2011;6:1879-86.

3. Tonelli M, Wiebe N, Culleton B, et al. Chronic kidney disease and mortality risk: a systematic review. J Am Soc Nephrol 2006;17:2034-47.

4. Go AS, Chertow GM, Fan D, et al. Chronic kidney disease and the risks of death, cardiovascular events, and hospitalization. $N$ Engl $J$ Med 2004;351:1296-305.

5. Webster AC, Nagler EV, Morton RL, et al. Chronic Kidney Disease. Lancet 2017;389:1238-52.

6. Prasad GV. Metabolic syndrome and chronic kidney disease: Current status and future directions. World J Nephrol 2014;3:210-9.

7. Choudhury G, Rabinovich R, MacNee W. Comorbidities and systemic effects of chronic obstructive pulmonary disease. Clin Chest Med 2014;35:101-30.

8. Barnes PJ, Celli BR. Systemic manifestations and comorbidities of COPD. Eur Respir J 2009;33:1165-85.

9. Incalzi RA, Corsonello A, Pedone C, et al. Chronic renal failure: a neglected comorbidity of COPD. Chest 2010;137:831-7.

10. van Gestel YR, Chonchol M, Hoeks SE, et al. Association between chronic obstructive pulmonary disease and chronic kidney disease in vascular surgery patients. Nephrol Dial Transplant 2009;24:2763-7.

11. Chen CY, Liao KM. Chronic obstructive pulmonary disease is associated with risk of chronic kidney disease: a nationwide casecohort study. Sci Rep 2016;6:25855.

12. Yoshizawa T, Okada K, Furuichi S, et al. Prevalence of chronic kidney diseases in patients with chronic obstructive pulmonary disease: assessment based on glomerular filtration rate estimated from creatinine and cystatin C levels. Int J Chron Obstruct Pulmon Dis 2015;10:1283-9.

13. Kim SK, Hur KY, Choi YH, et al. The Relationship between lung function and metabolic syndrome in obese and non-obese korean adult males. Korean Diabetes J 2010;34:253-60.

14. Levey AS, Stevens LA, Schmid CH, et al. A new equation to estimate glomerular filtration rate. Ann Intern Med 2009;150:604-12.

15. Delanaye P, Glassock RJ, Pottel $\mathrm{H}$, et al. An age-calibrated definition of chronic kidney disease: rationale and benefits. Clin Biochem Rev 2016;37:17-26.

16. Vogelmeier CF, Criner GJ, Martinez FJ, et al. Global strategy for the diagnosis, management, and prevention of chronic obstructive lung disease 2017 report: GOLD executive summary. Eur Respir J 2017;49:1700214.

17. Ehrlich SF, Quesenberry CP, Van Den Eeden SK, et al. Patients diagnosed with diabetes are at increased risk for asthma, chronic obstructive pulmonary disease, pulmonary fibrosis, and pneumonia but not lung cancer. Diabetes Care 2010;33:55-60.

18. Baffi CW, Wood L, Winnica D, et al. Metabolic syndrome and the lung. Chest 2016;149:1525-34.

19. Lucove J, Vupputuri S, Heiss G, et al. Metabolic syndrome and the development of CKD in American Indians: the Strong Heart Study. Am J Kidney Dis 2008;51:21-8.

20. Chen J, Muntner P, Hamm LL, et al. The metabolic syndrome and chronic kidney disease in U.S. adults. Ann Intern Med 2004;140:167-74.

21. Tsai WC, Wu HY, Peng YS, et al. Risk factors for development and progression of chronic kidney disease: a systematic review and exploratory meta-analysis. Medicine 2016;95:e3013.

22. Tanaka S, Tanaka T, Nangaku M. Hypoxia and dysregulated angiogenesis in kidney disease. Kidney Dis 2015;1:80-9.

23. Tanaka S, Tanaka T, Nangaku M. Hypoxia as a key player in the AKIto-CKD transition. Am J Physiol Renal Physiol 2014;307:F1187-95.

24. Wu L, Ma L, Nicholson LF, et al. Advanced glycation end products and its receptor (RAGE) are increased in patients with COPD. Respir Med 2011;105:329-36.

25. Polverino $\mathrm{F}$, Laucho-Contreras ME, Petersen $\mathrm{H}$, et al. A pilot study linking endothelial injury in lungs and kidneys in chronic obstructive pulmonary disease. Am J Respir Crit Care Med 2017;195:1464-76.

26. Sin DD, Man SF. Why are patients with chronic obstructive pulmonary disease at increased risk of cardiovascular diseases? The potential role of systemic inflammation in chronic obstructive pulmonary disease. Circulation 2003;107:1514-9.

27. Barnes PJ, Shapiro SD, Pauwels RA. Chronic obstructive pulmonary disease: molecular and cellular mechanisms. Eur Respir $J$ 2003;22:672-88.

28. Shlipak MG, Fried LF, Crump C, et al. Elevations of inflammatory and procoagulant biomarkers in elderly persons with renal insufficiency. Circulation 2003;107:87-92. 